\title{
THE STRANGE CASE OF THE ANKHPAKHERED MUMMY: RESULTS OF AMS ${ }^{14} \mathrm{C}$ DATING
}

\author{
G Quarta ${ }^{1,2} \bullet \mathrm{S} \mathrm{Malgora}^{3} \bullet \mathrm{M} \mathrm{D}^{\prime} \mathrm{Elia}^{1} \bullet \mathrm{V}$ Gaballo $^{1} \bullet \mathrm{E} \mathrm{Braione}^{1} \bullet \mathrm{L} \mathrm{Maruccio}^{1} \bullet \mathrm{C} \mathrm{Corvaglia}^{1} \bullet$ \\ L Calcagnile $^{1}$
}

ABSTRACT. The ancient Egyptian mummy discovered in the wooden coffin of Ankhpakhered, priest of the god Min, has been studied at CEDAD (Centre for Dating and Diagnostics) at the University of Salento, Italy. The CT scan, performed by the multidisciplinary team of the Mummy Project of Milan, highlighted unusual features of the mummy, suggesting a reuse of the sarcophagus. Furthermore, specimens were taken via endoscopy for accelerator mass spectrometry (AMS) radiocarbon dating and Fourier transform infrared (FTIR) analyses, which have been carried out at CEDAD.

\section{INTRODUCTION}

The Ankhpakhered mummy of ancient Egypt and the wooden coffin in which it is contained have been part of the collection of the Civic Museum of Asti, Italy, since the early 1900s thanks to a donation by the Vergano family (Leospo 1986). The anthropomorphic coffin has been dated, based on iconography and construction technique, to the period between the 22nd and 23rd dynasties (945$715 \mathrm{BC}$ ). A hieroglyphic inscription found on the coffin assigns the mummy to Ankhpakhered, a priest of the god Min. Nevertheless, the mummy shows unusual features that were revealed by Xray radiography performed during the restoration and by a CT scan performed by the Mummy Project. These features suggest a possible reuse of the coffin.

To investigate this issue, a radiocarbon dating campaign was planned by selecting, through endoscopy, different samples of bones and vegetal remains to be submitted for accelerator mass spectrometry (AMS) ${ }^{14} \mathrm{C}$ dating analyses carried out at CEDAD. The primary aim of this study was to establish the age of the mummy compared to the age of the coffin, as determined by archaeological considerations.

\section{ARCHAEOLOGICAL INFORMATION}

In 2008, for the exhibition "URSUNU, Great Doctors of Ancient Egypt, Diseases and Cures in the Land of the Pharaohs" organized by Sabina Malgora (Malgora 2008), the coffin and its contents underwent a conservative restoration campaign. The wooden anthropomorphic coffin (Figure 1) consists of a cover and a base with rich decorations and hieroglyphic inscriptions. According to archaeological evaluation, based on analysis of the construction technique and iconography, the coffin has been dated to the period between the 22nd and 23rd dynasties, i.e. 945 and 715 BC. Furthermore, because of the hieroglyphic inscription on the coffin, it has been possible to ascribe it to Ankhpakhered, a priest of the god Min, protector of human, animal, and plant fertility.

Inside the coffin, a 165-cm-long mummy was found in a chrysalis-like shape (Figure 1). It is covered by rough linen bandages and is damaged in the upper-right part of the chest, suggesting, together with the absence of a shroud (a typical element of Egyptian mummies), the activity of amulet thieves. Furthermore, during the restoration work, some preliminary analyses carried out on the mummy revealed that the bandages hide an unusual configuration status of the body, suggesting a

${ }^{1}$ CEDAD-Department of Engineering for Innovation, University of Salento, via per Monteroni, 73100, Lecce, Italy.

${ }^{2}$ Corresponding author: Email: gianluca.quarta@unisalento.it.

${ }^{3}$ Curator Egyptian Section of Buonconsiglio Castle, Trento, and co-director Mummy Project, Milan, Italy.

(c) 2013 by the Arizona Board of Regents on behalf of the University of Arizona

Proceedings of the 21st International Radiocarbon Conference edited by A J T Jull \& C Hatté

RADIOCARBON, Vol 55, Nr 2-3, 2013, p 1403-1408 


\section{G Quarta et al.}
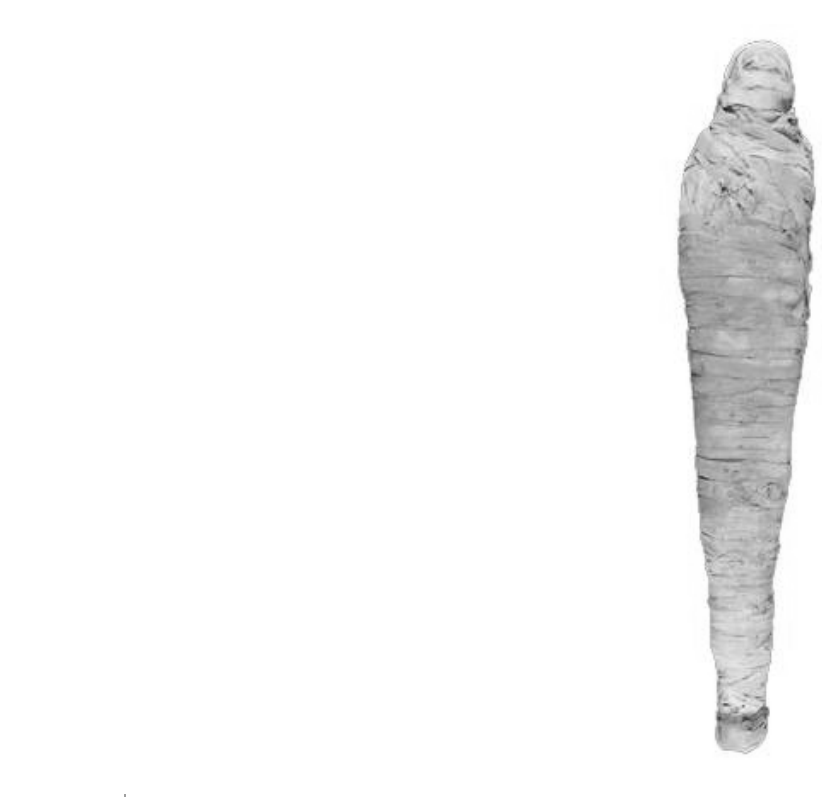

Figure 1 External view of the coffin and of the mummy

reuse of the coffin in more recent times. As a preliminary step of the following restoration campaign, $\mathrm{X}$-ray radiography and CT scan studies were planned in order to assess the status of the human remains wrapped in the linen bandages (Malgora and Pieri 2010, 2013; Malgora 2012a,b,c).

\section{X-RAY RADIOGRAPHY AND TOMOGRAPHY}

X-ray radiography revealed, immediately and surprisingly, that wrapped in the bandages was a skeleton but not a mummified body, since no evidence of the presence of mummified soft tissues was found (Figure 2). Furthermore, the skeleton bones were not in their anatomical order but were put together in quite a rough manner. These results suggested a possible reuse of the coffin and led to the planning of further analyses such as X-ray tomography at the Fatebenefratelli Hospital in Milan in order to better assess the positions of the different bones and the structure of the skeleton. Volumetric acquisitions of the skull, the full body, and the extremities were separately performed, and overall 2950 pictures were obtained. These images were then post-processed in order to obtain a 3D, digital reconstruction of the skeleton. The results clearly confirm the first data obtained by the preliminary radiographic work, namely that inside the bandages there was an "ensemble" of bones and not a mummified body. Furthermore, tomographic analyses have shown that the skeleton lies on a stretcher composed of 21 reeds, with 2 of them penetrating into and supporting the skull (Figure 3).

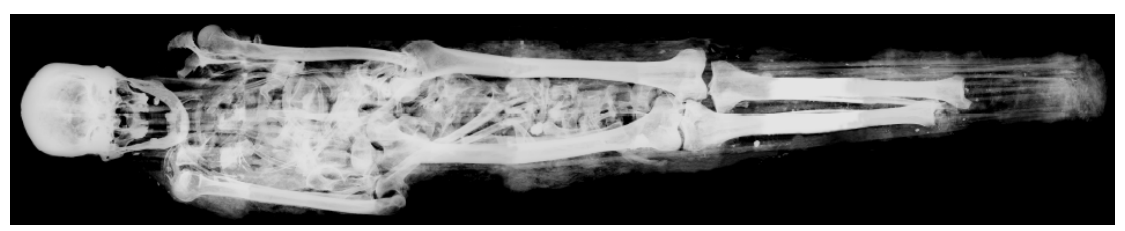

Figure 2 X-ray radiography of the body 

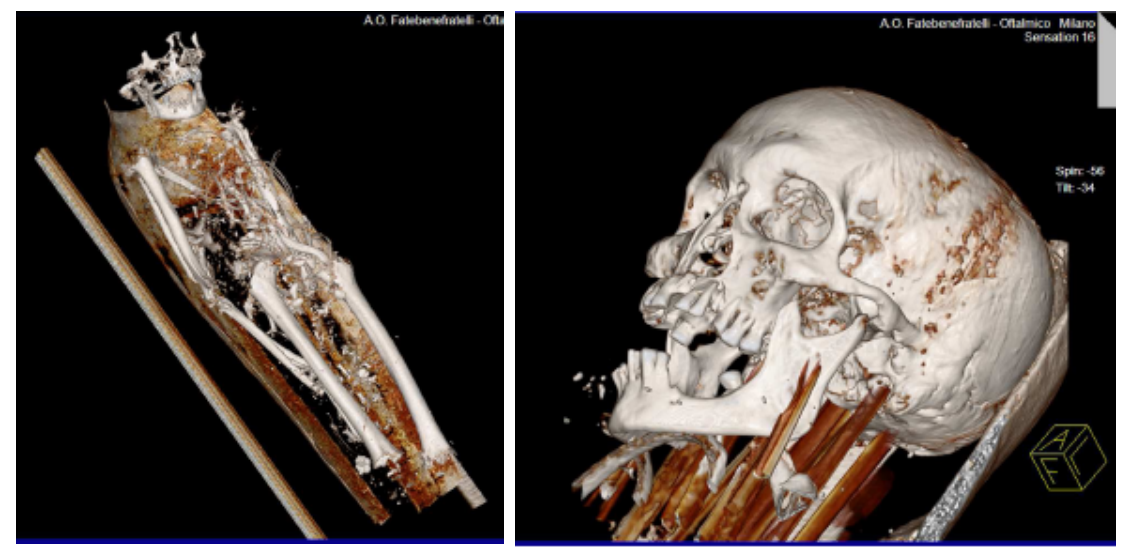

Figure 3 3D reconstruction of the body and skull

The feet are not in position but are placed between the femurs, the pelvis is placed between the shoulder blades, and the spine is broken up into individual vertebrae that are scattered within the thoracic cage, along with the hand bones and some teeth. The jaw is dislocated from the left side of the skull. Considering the social role expected for a priest, the arms are positioned in an unusual way when compared to how such remains are usually found. Therefore, these results strongly support the idea that the coffin could have been reused, and thus the remains found inside it were younger than the age of the coffin. In order to solve the mystery, an endoscopy was performed to collect samples for further analyses (Malgora and Bernardo 2013), mainly for ${ }^{14} \mathrm{C}$ dating.

\section{RADIOCARBON DATING ANALYSES}

Twelve samples were taken from the external part of the "mummy" as well as from the inner parts. In particular, materials from the inner part of the bandage were sampled through endoscopy carried out at the Melloni hospital in Milano, Italy, by the team of Prof Bernardo. Samples of bones, textiles from the bandages, and reeds were selected for AMS ${ }^{14} \mathrm{C}$ dating analyses (Table 1) carried out at CEDAD (Centre for Dating and Diagnostics) at the University of Salento (Calcagnile et al. 2004). To remove external contaminants, vegetable samples (i.e. reeds and textiles) were processed following the standard ABA (acid-base-acid) treatment routinely used at CEDAD (D'Elia et al. 2004). Collagen was extracted from bone samples following the standard Longin protocol (Longin 1971). To assess the preservation status of the extracted collagen, FTIR analyses were carried out following a protocol described in detail elsewhere (D'Elia et al. 2007; Gianfrate et al. 2007). In brief, after demineralization of the bone with $1 \% \mathrm{HCl}$, the organic fraction is dissolved as gelatin in acidic hot water and collagen is filtered. A drop of collagen is then taken, dried, and submitted to FTIR analyses, which were carried out at the Chemistry-Physics Laboratory of the University of Salento using a Perkin Elmer Spotlight ${ }^{\mathrm{TM}}$ FTIR spectrometer in attenuated total reflection (ATR) mode.

Afterwards, the purified sample material was sealed in a quartz tube with copper oxide and silver wool, and then converted into carbon dioxide by combustion at $900{ }^{\circ} \mathrm{C}$. The extracted $\mathrm{CO}_{2}$ was then reduced at $600{ }^{\circ} \mathrm{C}$ to graphite by using hydrogen as a reducing agent and iron powder as a catalyst. The ${ }^{14} \mathrm{C}$ age of the samples was then determined using the AMS system at CEDAD (Calcagnile et al. 2005). 


\section{G Quarta et al.}

Table 1 Summary of selected samples and measured ${ }^{14} \mathrm{C}$ ages.

\begin{tabular}{llll}
\hline Sample ID & Material & Sampled area & ${ }^{14}$ C age (BP) \\
\hline LTL6070A & Bone & Chest & $2212 \pm 45$ \\
LTL6070T & Textile & Chest & $2125 \pm 55$ \\
LTL6070S & Seed & Chest & $2181 \pm 45$ \\
LTL6072A & Bone & Skull & $2170 \pm 45$ \\
LTL6072T & Textile & Skull & $2240 \pm 50$ \\
LTL6074A & Reed & Feet & $2168 \pm 35$ \\
LTL6074B & Reed & Feet & $2250 \pm 40$ \\
LTL6075A & Textile & Skull & $2272 \pm 45$ \\
LTL6075B & Textile & Skull & $2162 \pm 45$ \\
LTL6076A & Textile & Chest & $2134 \pm 40$ \\
LTL6077A & Textile & Feet & $2258 \pm 45$ \\
LTL6078A & Textile & Skull & $2187 \pm 40$ \\
\hline
\end{tabular}

\section{Radiocarbon Dating Results}

All the FTIR spectra obtained from bone collagen exhibited strong and intense infrared (IR) absorption peaks, characteristic of collagen functional groups (Susi et al. 1971; Brodsky-Doyle et al. 1975). By comparing the obtained spectra with those available in the literature we can assess the good preservation status of the samples (Gianfrate et al. 2007). Figure 4 shows a typical FTIR spectrum obtained from sample LTL6070A. The positions of the typical "fingerprint" IR bands characteristics of collagen are indicated by arrows. Similar spectra were obtained for all analyzed samples.

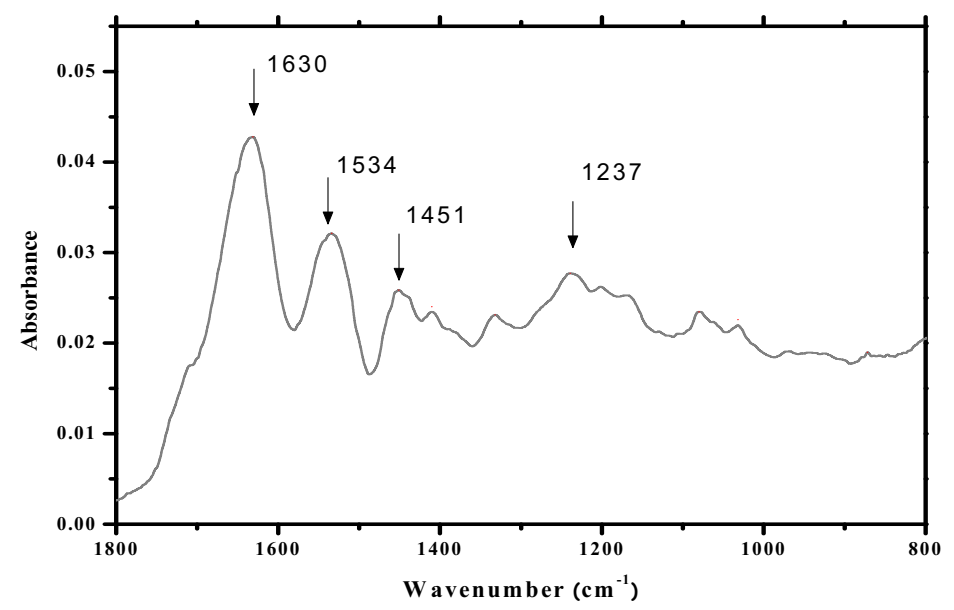

Figure 4 FTIR spectrum obtained from the collagen extracted from sample LTL6070A. Arrows indicate the position of typical IR absorption bands of collagen.

AMS measurement results are given as uncalibrated ${ }^{14} \mathrm{C}$ ages in Table 1 . Conventional ${ }^{14} \mathrm{C}$ ages were converted to calendar ages by using the OxCal v 4.1 software (Bronk Ramsey 2009) and IntCal09 calibration curve (Reimer et al. 2009). Figure 5 shows the calibration results. It can be immediately observed that all the analyzed samples — bones, textiles, reeds, and seeds - give consistent and overlapping ages falling between the 4 th and 1 st centuries BC. A combined age was then calculated by using the $R_{-}$Combine function of OxCal after verifying that the data passed the $\chi^{2}$ test. A combined age of between 360 and 200 BC was obtained with a confidence level of $95.4 \%$ 
(Figure 6). ${ }^{14} \mathrm{C}$ dating results thus indicate that the "mummy" is significantly younger than the coffin, which, as previously discussed, is stylistically dated to $945-715 \mathrm{BC}$.

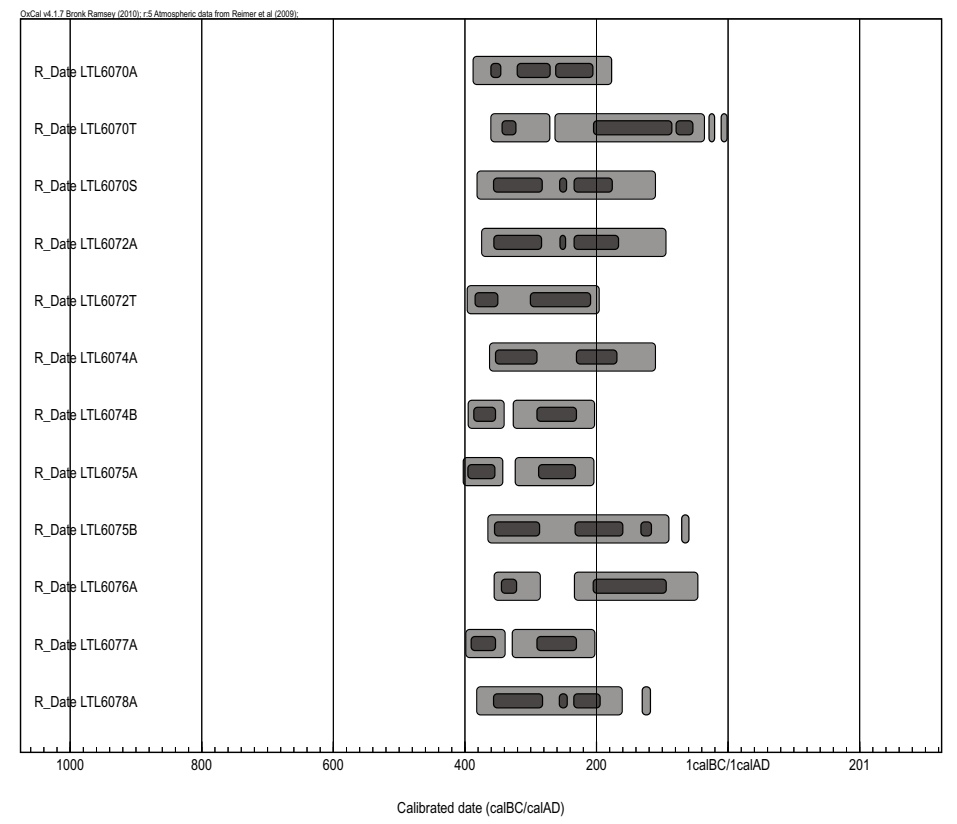

Figure 5 Calibrated ${ }^{14} \mathrm{C}$ dates

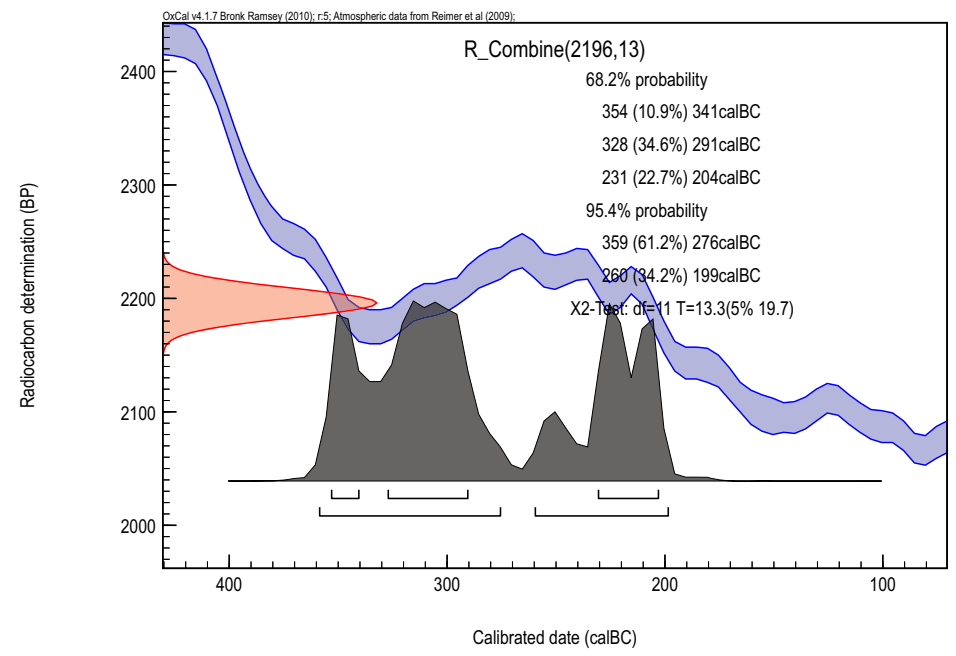

Figure 6 Combination of the $12{ }^{14} \mathrm{C}$ ages

\section{CONCLUSION}

The bandaged body found inside the coffin of Ankhpakhered was analyzed at CEDAD. Samples of bones, reeds, and textiles were taken through endoscopy. AMS ${ }^{14} \mathrm{C}$ dating on different kinds of samples taken from various parts of the body showed consistent ages, allowing us to date the remains to 


\section{G Quarta et al.}

360-200 BC. The age difference of the body compared to the coffin (stylistically dated to 945$715 \mathrm{BC})$ suggests that the coffin was reused at a later date.

\section{ACKNOWLEDGMENTS}

We wish to thank Dr Gabriele Giancane, University of Salento, for performing the FTIR analyses. For the CT scan and the endoscopy, we thank the Mummy Project team: Prof Luca Bernardo, head of the Department of Maternal Fetal Science; Dr Antonio Pieri, neurosurgeon; Dr Giosuè Ceriani, medical director of Radiology; and Paolo Scali, technician of SC Radiology at the same institution; Dr Chantal Milani, forensic dentist; and Dr Davide Bertocco for the revision of the CT scan images. We thank the Lombardia region, in particular Dr Luciano Bresciani, counselor of the Department of Health (Assessorato Sanità). We thank the town of Asti, in particular, Dr Salvatore Leto, director of the Art and Culture Municipal Section of Asti at the time of the examination, and Dr Gianfranco Imerito, counselor of the Culture and Sport Municipal Section of Asti. At the Civic Museum of Asti, we thank Giuseppe Ponzone of the museum office, and the museum staff.

\section{REFERENCES}

Brodsky-Doyle B, Bendit EG, Blout ER. 1975. Infrared spectroscopy of collagen and collagen-like polypeptides. Biopolymers 14(5):937-57.

Bronk Ramsey C. 2009. Bayesian analysis of radiocarbon dates. Radiocarbon 51(1):337-60.

Calcagnile L, Quarta G, D'Elia M, Rizzo A, Gottdang A, Klein M, Mous DJW. 2004. A new accelerator mass spectrometry facility in Lecce, Italy. Nuclear Instruments and Methods in Physics Research B 223-224: 16-20.

Calcagnile L, Quarta G, D'Elia M. 2005. High resolution accelerator-based mass spectrometry: precision, accuracy and background. Applied Radiation and Isotopes 62(4):623-9.

D’Elia M, Calcagnile L, Quarta G, Rizzo A, Sanapo C, Laudisa M, Toma U, Rizzo A. 2004. Sample preparation and blank values at the AMS radiocarbon facility of the University of Lecce. Nuclear Instruments and Methods in Physics Research B 223-224:278-83.

D'Elia M, Gianfrate G, Quarta G, Giotta L, Giancane G, Calcagnile L. 2007. Evaluation of possible contamination sources in the ${ }^{14} \mathrm{C}$ analysis of bone samples by FTIR spectroscopy. Radiocarbon 49(2):201-10.

Gianfrate G, D’Elia M, Quarta G, Giotta L, Valli L, Calcagnile L. 2007. Qualitative application based on IR spectroscopy for bone sample quality control in radiocarbon dating. Nuclear Instruments and Methods in Physics Research B 259(1):316-9.

Leospo E. 1986. Museo Archeologico di Asti. La Collezione Egizia. Torino: Regione Piemonte. In Italian.

Longin R. 1971. New method of collagen extraction for radiocarbon dating. Nature 230(5291):241-2.

Malgora S. 2008. Ur Sunu. Grandi dottori dell'Antico Egitto. Malattie e cure nella terra dei Faraoni. Vercelli: Fondazione Museo delle Antichità Egizie di Torino. In Italian.

Malgora S. 2012a. Un corpo per l'eternità. In: Cerasetti
B, Lamberg-Karlovsky K, editors. My Life is Like the Summer Rose. Maurizio Tosi e l'Archeologia come modo di vita. British Archaeological Reports. Oxford: Archaeopress. p 180-94.

Malgora S. 2012b. La prima del Mummy Project. In: Modenesi G, editor. Sotto l'ala di Thot. Contributi alla conoscenza dell'antico Egitto. Milano. p 105-16.

Malgora S. 2012c. La mummia di Ankhpakhered. Indagini mediche del Mummy Project sul reperto del Civico Museo di Asti. In: Boano R, Rabino Massa E, editors. Mummie Egizi in Piemonte. Storia ed attualità in ambito egittologicoed antropologico. Torino: Museo regionale di Scienze Naturali. p 63-5. In Italian.

Malgora S, Bernardo L. 2013. The Mummy Project. The case of Ankhpakhered: the endoscopy. In: Gill-Frerking H, Zink A, Rosendahl W, editors. Yearbook of Mummy Studies. Volume II. Forthcoming.

Malgora S, Pieri A. 2010. An Italian mummy mystery. Ancient Egypt 10(6):28-31.

Malgora S, Pieri A. 2013. The Mummy Project. The case of Ankhpakhered: CT scan analysis. In: Gill-Frerking H, Zink A, Rosendahl W, editors. Yearbook of Mummy Studies. Volume II. Forthcoming.

Reimer PJ, Baillie MGL, Bard E, Bayliss A, Beck JW, Blackwell PG, Bronk Ramsey C, Buck CE, Burr GS, Edwards RL, Friedrich M, Grootes PM, Guilderson TP, Hajdas I, Heaton T, Hogg AG, Hughen KA, Kaiser KF, Kromer B, McCormac FG, Manning SW, Reimer RW, Richards DA, Southon JR, Talamo S, Turney CSM, van der Plicht J, Weyhenmeyer CE. 2009. IntCa109 and Marine09 radiocarbon age calibration curves, 0-50,000 years cal BP. Radiocarbon 51(4): 1111-50.

Susi H, Ard JS, Carroll RJ. 1971. Hydration and denaturation of collagen as observed by infrared spectroscopy. Journal of the American Leather Chemists Association 66(11):508-19. 